\title{
Die Lernmaschine
}

Einst versorgten die Schlachthöfe von La Villette die Stadt mit Fleisch. Dann entstand auf den 55 Hektaren im Nordosten ein Park der Superlative aus Technik und Wissenschaft, Kunst und Kultur, Vergnügen und Freizeit. Zu den Prunkstücken der urbanen Spielwiese gehören die Cité des Sciences et de l'Industrie, die Grande Halle, letzter gusseiserner Zeuge der vergangenen Cité du Sang und das jüngste Bauwerk, die Cité de la Musique. Novemberlaub und futuristische Architektur spiegeln sich auf der Aussenhaut der silbernen Kinokugel, La Géode, die mit ihrer Imax-Technologie die Zuschauer in Akteure verwandelt. «Paris ist ein herrliches Schiff, beladen mit Verstand», befand Honoré de Balzac. Die Präsidenten der Republik haben ihn beim Wort genommen und in den 80er Jahren ein pädagogisches Meisterwerk geschaffen, das Erholung und Unterricht didaktisch hervorragend vereinigt. Viele Schulklassen und Familien sind unterwegs, sie verpflegen sich in den zahlreichen Restaurants, reisen mit NASA-Astronauten zum Hubble Teleskop, betrachten die fernsten Galaxien, ducken sich vor mächtigen Sauriern im 3D-Format, tauchen ein in die ScienceFiction-Welt oder studieren Gentechnologie und Wissenschaftsgeschichte. Interaktive Lernkonsolen, Biblio- und Videotheken, sowie zahlreiche MultimediaDokumente lassen keine Wünsche offen. Rolltreppen befördern Tausende über die fünf transparenten Etagen der Lernfabrik, die ein perfektes Orientierungssystem miteinander verbindet.

Eine grosse Ausstellungsfläche nennt sich Cité de la Santé, wo an fünf Tagen in der Woche auch persönliche Beratungsgespräche stattfinden. Hier gibt es monatliche Programme mit originellen Animationen, Vorträgen und Filmen. «Les vieillards sont-ils des hommes?», hat Simone de Beauvoir provokativ gefragt. Ab wann ist man alt, was heisst alt sein, zu Hause und im Heim, fragt eine kleine Schau mit schönen Porträts alter Menschen. «L'homme est un irréversible incarné» hält die Begleitbroschüre fest, geistreich und informativ, wie alles hier. Natürlich kommt auch die Prävention nicht zu kurz. Eine lange Wand bietet Informationen von Aids bis zur Zwangsehe, Tipps zur Ernährung, sieben goldene Regeln zum Generikagebrauch und nützliche Kontaktadressen zu fast jedem Problem.

Die Cité bietet eine überwältigende Fülle von Informationen. Die Bilderflut ist enorm, auch dort wo berühren ausdrücklich erlaubt ist. Kluge Experi- mente machen komplexe Inhalte verständlich, Lernen soll Spass machen. Wenn Infotainement zur Bildung beiträgt, dann hier. Wie immer sind Vorwissen und nachträgliche Vertiefungen unverzichtbar, wo mehr als oberflächliche Eindrücke bleiben sollen. Der Wissensbasar eröffnet Zugänge zum Verständnis unserer Welt, mehr zu verlangen wäre unrealistisch. Das 150-Jahre-Jubiläum von Darwins Evolutionstheorie hat mancherorts Spuren hinterlassen. Ohne seine Vorstellungen sähe dieses Lernforum ganz anders aus. 2008 hat das Erziehungsministerium in La Villette eine Lehrerkonferenz zum Thema «Enseigner l'Evolution» organisiert. Zahlreiche Schulen und Lehrer waren zuvor ungefragt mit einem «Atlas de la Création» beliefert worden. Einem illustrierten Acht-KiloWerk, mit dem Ziel, die moderne Biologie als antireligiöses Lügengewebe zu diffamieren. Die aufwendige Aktion türkisch-islamischer Integristen und evangelikaler Kreise hat gemäss Teilnehmer der Tagung wie ein Elektroschock gewirkt. Auch das laizistische Frankreich kennt fundamentalistische Bewegungen, die vor allem junge Menschen zu überzeugen versuchen. Beruflich schlecht integrierte Jugendliche verweigern demonstrativ eine rationale Auseinandersetzung. Die Lehre Darwins dient auch im Internet als idealer Blitzableiter für frustrierte Banlieue-Bewohner und «Intelligent Design» Adepten, die sehr gezielt die alte Dominanz der Kirchen wiederherstellen wollen. Das Konzept der Cité des Sciences wird durch die schwerreiche Tempelton-Stiftung herausgefordert. Diese finanziert lieber Suchexpeditionen nach der Arche Noah als Balzacs Schiff der Vernunft. Damit wird die Cité mehr denn je zum Ort gesellschaftlicher Auseinandersetzungen. Das ist auch gut so, denn vielleicht ging in der Baueuphorie von La Villette vergessen, dass ein Projekt der Aufklärung kein Perpetuum mobile sein kann, das reibungslos von selber weiterläuft. Ohne soziale Gerechtigkeit und ohne Ökologie ist wissenschaftlicher Fortschritt auf lange Sicht nicht zu haben. Für Jules Verne waren Klimakatastrophen, Überbevölkerung und bedrohte Biodiversität noch kein Thema. Die Cité ehrt sein Andenken, nennt aber auch eindringlich die bedrohlichen Seiten von Geldgier, Machtstreben und technischer Ausbeutung. Vor der Géode praktiziert eine Gruppe Chinesinnen TaiChi. Was sie über die Cité denken? Sie lächeln höflich.

Erhard Taverna 